\title{
Histological Study of the Possible Protective Effect of Lycopene on Glucocorticoid-Induced Osteoporosis in Adult Male Albino Rat
}

\author{
GEORGE S. MITYAS, M.Sc.; SADIKA M. TAWFIK, M.D.; NADIA A. EL-BAKERY, M.D. and \\ EHSAN F. SALAH, M.D.
}

The Department of Histology, Faculty of Medicine, Tanta University, Egypt

\begin{abstract}
Background: Osteoporosis is one of the most commonly occurring bone diseases characterized by decrease in bone mass and increase bone resorption leading to fractures, severe pain and deformities. Glucocorticoid-induced osteoporosis results from long-term and high dose use. Lycopene is an unsaturated carotenoid that gives tomatoes and other fruits their red color. It was reported that it is a natural antioxidant and was associated with the prevention of many chronic diseases and cancers.
\end{abstract}

Aim of Study: This work was performed to study the possible protective effect of lycopene against glucocorticoidinduced osteoporosis in adult male albino rat.

Material and Methods: 40 adult male albino rats were used that divided equally into four main groups: Group I (control group) was subdivided equally into two subgroups (I-A \& I-B), Group II received lycopene orally $30 \mathrm{mg} / \mathrm{kg}$ once daily for 8 weeks, Group III received prednisolone orally $20 \mathrm{mg} / \mathrm{kg}$ once daily for 8 weeks, Group IV concomitantly received lycopene and prednisolone orally once daily at the same previous doses for 8 weeks. At the end of experiment, femur heads of all animals were obtained and processed for histological study and stained with Hematoxylin \& eosin, Mallory Trichrome and for scanning electron microscope study.

Results: Light microscopic examination revealed structural changes in femur head of Group III in the form of discontinuous thin trabeculae of cancellous bone with apparent faintly stained matrix with multiple pores inside trabeculae associated with minor fractures, wide bone marrow spaces were seen between trabeculae containing abundant clear areas, the endosteal surface showed irregular eroded surface. Regarding Mallory stained sections; they showed decrease collagen fibers contents with their irregular distribution in bone matrix. Scanning electron microscopic specimens showed discontinuous thin and blind ended cancellous bone trabeculae containing some areas of decreased electron density with multiple pores and minor fractures inside them. Wide bone marrow spaces were seen between trabeculae lined with irregular eroded endosteal surface; which revealed the evident of prednisolone induced osteoporosis. Group IV specimens revealed partial preservation

Correspondence to: Dr. George S. Mityas, The Department of Histology, Faculty of Medicine, Tanta University, Egypt of the normal structure of cancellous bone of femur head to some extent.

Conclusion: Osteoporosis resulted from glucocorticoids in adult male albino rats can be partially minimized by lycopene co-administration.

Key Words: Osteoporosis - Prednisolone - Lycopene - Rat.

\section{Introduction}

OSTEOPOROSIS is a skeletal disorder characterized by compromised bone strength. It causes bone resorption and fractures, leading to severe pain, deformities, and in certain cases, secondary complications that may be fatal. Bone strength primarily reflects the integration of bone density and bone quality [1]

Glucocorticoids (GCs) are used most extensively as anti-inflammatory and immunosuppressive drugs to treat a variety of diseases such as inflammation, cancer, and autoimmune disorders. However, long-term and large doses of oral treatment with glucocorticoids are associated with an increased risk of osteoporosis or fracture. So, Glucocorticoid-Induced Osteoporosis (GIOP) is the main cause of secondary osteoporosis, as GCs have been reported to exhibit detrimental effects on the proliferation and function of osteoblasts [2-4]

Lycopene is an open-chain, unsaturated carotenoid that imparts red color to tomatoes and other fruits. It was found to be a natural antioxidant and was associated with the prevention of some chronic diseases including cardiovascular diseases, prostate and gastrointestinal tract cancers in human. It was stated that the daily consumption of lycopene decreases oxidative injury, bone resorption and increases intake of calcium, niacin, and vitamins $\mathrm{A}, \mathrm{D}$, and $\mathrm{K}$ in postmenopausal women. In addition, it was reported that lycopene treatment can inhibit 
bone loss and increases bone strength in ovariectomized rats [5-7].

\section{Material and Methods}

This work was carried out at Histology Department, Faculty of Medicine, Tanta University and at The Electron Microscopic Unit, Faculty of Medicine, Tanta University from 2016-2018.

\section{I- Experimental animals:}

This study was carried out on 40 adult male albino rats. Their weights ranged between 150 $200 \mathrm{~g}$. The animals were housed under similar conditions of good illumination and ventilation conditions in the animal house. They were housed in suitable clean properly plastic cages with mesh wire. They were fed on a similar commercial laboratory diet and water. They were carefully selected free of gait disturbance, swollen joints or limping [8]. The animals were acclimatized to their environment at least one week before starting the experiment.

The animals were divided into four groups as follows:

- Group I (the control group): It included 10 rats used for histological study of the bone. They were divided into 2 subgroups (Subgroup I-A, Subgroup I-B):

- Subgroup I-A: Included 5 rats received no medications.

- Subgroup I-B: Included 5 rats received distilled water $2.2 \mathrm{ml} / 100 \mathrm{gm} \mathrm{BW}$ per day (the solvent of both prednisolone and lycopene capsule) orally by gastric tube for the same period as experimental animals.

- Group II (the lycopene group): It included 10 rats given lycopene orally at a dose of $30 \mathrm{mg} / \mathrm{kg}$ BW once daily for 8 weeks [7]. It was purchased as (Lycopene-50 capsules, manufactured and distributed by KRK Supplements in USA, Sold and Fulfilled by Amazon), each capsule contained $50 \mathrm{mg}$ lycopene and its content was suspended in $20 \mathrm{ml}$ distilled water to be concentrated as $2.5 \mathrm{mg} /$ $1 \mathrm{ml}$ distilled water. So, each rat received $1.2 \mathrm{ml}$ of prepared solution/100gm BW per day which was given orally by gastric tube. The amount of dose-response study in which the maximal degree of protection from corticosteroid induced osteoporosis was reported in the study of Haidong et al., [7] .

- Group III (the osteoporosis induced group): It included 10 rats. Induction of osteoporosis was performed by giving prednisolone orally at a dose of $20 \mathrm{mg} / \mathrm{kg} \mathrm{BW}$ once daily for 8 weeks [9] .

- It was purchased as (Hostacortin $\mathrm{H}$ tablets, produced by Sanofi-aventis/Egypt S.A.E under license of Sanofi-aventis/Germany), each tablet contained $5 \mathrm{mg}$ prednisolone and was dissolved in $2.5 \mathrm{ml}$ distilled water to be concentrated as $2 \mathrm{mg} / 1 \mathrm{ml}$ distilled water. So, each rat received $1 \mathrm{ml}$ of prepared solution/100gm BW per day which was given orally by gastric tube. This dose was found to induce maximal degree of osteoporosis as reported by Ogoshi et al., [9].

- Group IV (the protective group): It included 10 rats given both lycopene orally at a dose of 30 $\mathrm{mg} / \mathrm{kg} \mathrm{BW}$ once daily and prednisolone orally at a dose of $20 \mathrm{mg} / \mathrm{kg} \mathrm{BW}$ once daily for 8 weeks.

\section{II- Specimen achievement:}

At the appropriate time after 8 weeks and 24 hours after the last dose, rats of all studied groups were anesthetized with intraperitoneal injection of sodium thiopental $200 \mathrm{mg} / \mathrm{kg} \mathrm{BW}[\mathbf{1 0 , 1 1 ]}$. Then, the head of each femur of all animals was carefully dissected out and processed for histological studies. The bodies of sacrificed animals were packed in a special package according to safety precautions and infection control measures and sent with the hospital biohazards.

\section{III- Histological study of the bone:}

The head of each femur of all animals was excised and cleaned from muscle attached, trimmed or dissected as appropriate then subjected to the following:

- The head of right femur of all animals was taken and immediately fixed in 10\% formal saline solution for 5 days. The specimens were washed by tap water for half an hour then they were decalcified in the chelating agent disodium EDTA solution [12]. The head of left femur of all animals was taken and immediately fixed in gluteraldehyde solution then prepared for scanning electron microscope.

\section{Decalcification method [13]:}

- Decalcification processes was carried by chelating agent, Ethylene Diamine Tetra Acetic acid (EDTA) where it binds with or absorb the calcium ions; it acts slowly but preserves all cellular components.

- EDTA disodium salt (10\%) or EDTA tetra sodium salts (14\%) are approaching saturation and can be simple aqueous or buffered solutions at a neutral $\mathrm{pH}$ of 7-7.4 or added to formalin. The 
time required to totally decalcify dense cortical bone may be 6-8 weeks or longer.

- Decalcification lasted for about 4 weeks, during which the solution was renewed every 2 days until the tissues had softened. The time for exposure to the decalcification will vary; closely monitor the progress is needed.

- The decalcified head of femur was cut longitudinally in a coronal plane along the central portion and specimens were processed to form paraffin blocks.

Serial sections of 5 micrometer thickness were obtained and subjected to the following:

A- Histological stained sections:

1- Haematoxylin and Eosin (H \& E) stain [14] : Was used to demonstrate the general histological structures of rat's head of femur among various experimental groups. Nuclei were stained dark blue, cytoplasm were stained varying degrees of pink.

2-Mallory's trichrome stain [15]: For demonstration of collagen fibers. Collagen fibers were stained blue, cytoplasm and nuclei were stained red.

All these sections were examined and photographed using Olympus light microscope (Tokyo, Japan) coupled to an Olympus digital camera (DXC-1850P, Tokyo, Japan) in Histology Department, Faculty of Medicine, Tanta University.

\section{B- Morphometric study and statistical analysis:}

The image analysis system was done by image analysis software program (Image J. version 1.48), it was used to measure the mean area percentage of collagen fiber contents in Mallory Trichrome stained sections in all groups. ANOVA test was done to compare different groups of our study with the control group.

\section{C- Scanning electron microscopic specimens:}

The head of femur specimens were subjected to the following steps $[\mathbf{1 6 , 1 7 ]}$ :

1- Fixation and cutting the samples: The specimens were rapidly fixed in $2.5 \%$ phosphate buffered glutaraldehyde ( $\mathrm{pH} 7.4)$ at $4^{\circ} \mathrm{C}$ for 2 hours followed by three rinses in the phosphate-buffer (each 10min). Then the head of femur specimens were cut longitudinally by a saw cutting device for hard tissue that was done in department of dental material, Faculty of Dentistry, Tanta University. Then, specimens were submerged in fixative $(2.5 \%$ glutaraldehyde and $1 \%$ formal- dehyde in phosphate buffer at $\mathrm{pH} 7.4$ ), initially at $37^{\circ} \mathrm{C}$, for $24-48 \mathrm{~h}$.

2- Critical Point Drying (CPD): Specimens were placed in a sample holder and subjected to a dehydration process using a graded series of solutions of acetone, or ethyl alcohols in concentrations typically from $15,30,50,70,90$, 95 , and $100 \%$ to gradually replace the water in the sample. Ethanol was substituted by admitting liquid $\mathrm{CO}_{2}$, at room temperature, to a committed pressure vessel, the CPD chamber. Liquid $\mathrm{CO} 2$ was allowed to escape intermittently to flush dissolved ethanol from the chamber. The highpressure $\mathrm{CO}_{2}$ gas was allowed to escape, leaving the samples dry and ready for mounting and coating.

3- Coating (sputtering of gold): Metal coating was applied to a specimen surface to aid signal generation but also to prevent the buildup of a charge on a non-conducting surface. Charging can cause displacement of the primary beam, resulting in some unsightly imaging artifacts. Samples were coated in a sputter coater to monitor the coating process to determine the thickness of coating being deposited. Gold was used as a coating material. A coating thickness up to a few nm is usually sufficient to form a sufficiently conducting surface, ensuring good distribution of metallic particles across the whole specimen surface.

4- Morphological imaging of the bone: Finally, the specimens were examined and photographed using JEOL-JSM-5200LV scanning electron microscope with microscopy suited camera at Electron Microscopic Unit, Faculty of Medicine, Tanta University.

\section{Histological Results}

\section{I- Light microscopic results:}

\section{A- Haematoxylin \& eosin stained sections:}

Group I: Control group (subgroup I-A \& subgroup I-B): Examination of $\mathrm{H} \& \mathrm{E}$ stained sections obtained from the head of femur of both subgroups I-A \& I-B were similar and showed the same histological picture which was identical to the wellknown histological structure of the epiphysis. There were normal anastomosing thick network of cancellous bone trabeculae having bone lamellae and osteocytes inside their lacunae. Smooth regular continuous endosteal surface of that trabeculae covered by osteoprogenitor and osteoblast cells was observed. Bone marrow spaces containing large number of hemopoietic cells were seen between trabeculae Fig. (1A-D). 


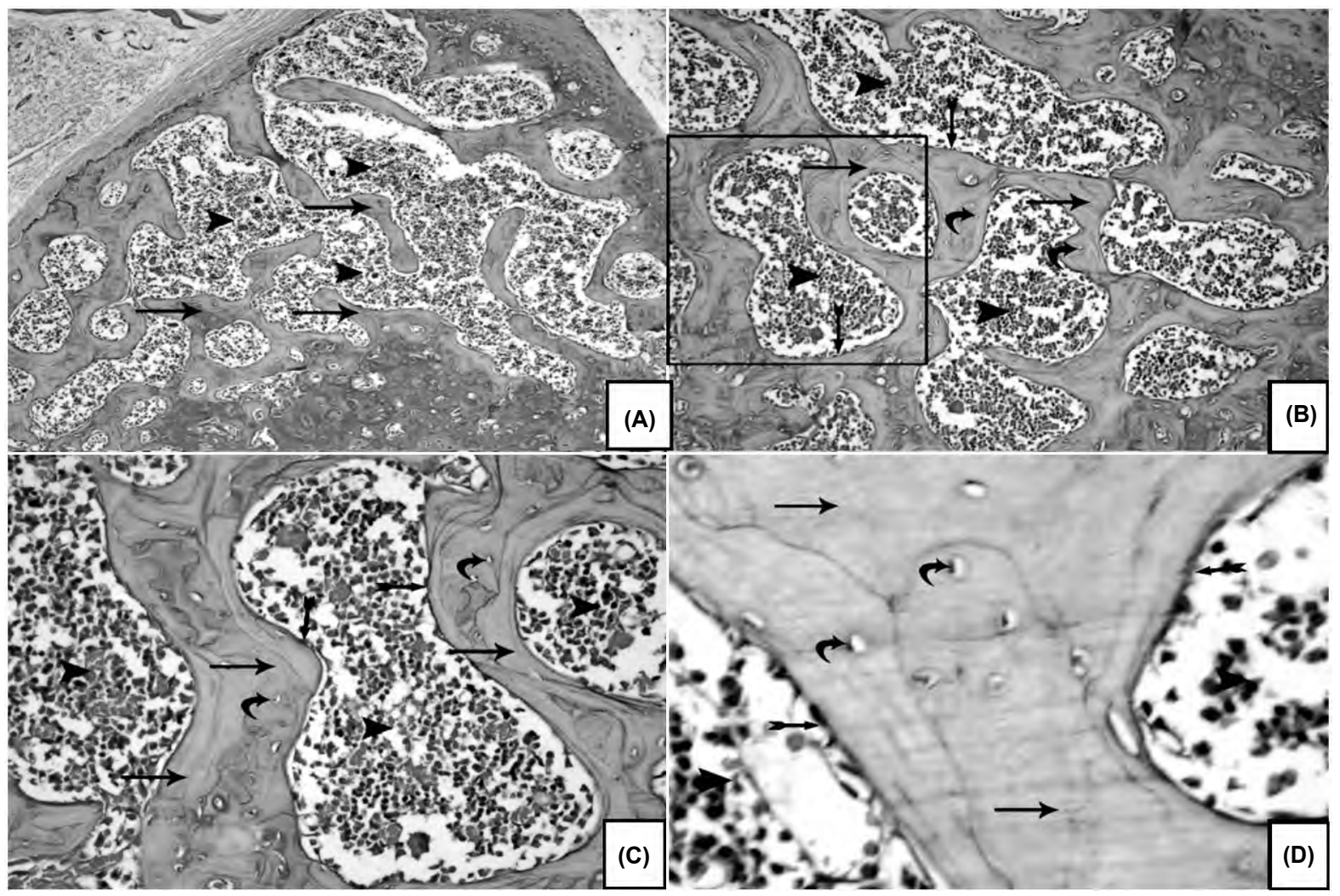

Fig. (1): A photomicrograph of a control rat head of femur showing anastomosing thick network of cancellous bone trabeculae (arrows), bone marrow spaces containing hemopoietic cells (arrow heads) and osteocytes inside their lacunae (curved arrows). Smooth regular endosteal surface is covered by osteoprogenitor cells (bifid arrows) (H \& E, 1A, X100, 1B X200, 1C X400 \& 1D X1000).

Group II: Lycopene group: Examination of sections obtained from the head of femur of this group revealed apparently the same histological picture as in the control group.

Group III: Osteoporosis induced group by prednisolone: Examination of sections obtained from the head of femur of this group revealed changes of different degrees of osteoporosis which were focal in some sections and diffused in others and were different from rat to other. These changes were in the form of discontinuous thin cancellous bone trabeculae with focal areas of apparent faintly stained matrix and pores. There were blind ended trabeculae associated with minor fissures and fractures. Osteocytes inside their apparently large lacunae and some empty lacunae were detected. Wide bone marrow spaces were seen between trabeculae containing less hemopoietic cells and abundant adipocytes than the control group, their lining endosteum showed irregular eroded surface Fig. (2A-D).

Group IV: Protective group (prednisolone + lycopene): Examination of sections obtained from the head of femur of this group revealed relatively less destructive changes than that were observed in Group III (osteoporosis induced group). There was also some degree of preservation of the normal histological structure which was variable from one animal to other. There were relatively thin trabeculae of cancellous bone and wide bone marrow spaces in between. Few small pores appeared inside the trabeculae. Apparent more osteocytes inside their lacunae were occasionally observed more than control group. Regular continuous endosteal surface was noticed Fig. (3A,B).

\section{B- Mallory trichrome stained sections:}

Group I: Mallory trichrome stained sections of both subgroups I-A \& I-B showed the same arrangement and distribution of the collagen fibers in the head of femur exhibited by blue coloration of bone matrix which was identical to the wellknown histological structure of the epiphysis Fig. $(4 \mathrm{~A}, \mathrm{~B})$.

Group II: Examination of sections obtained from the head of femur of this group revealed apparently the same histological picture as in the control group. 


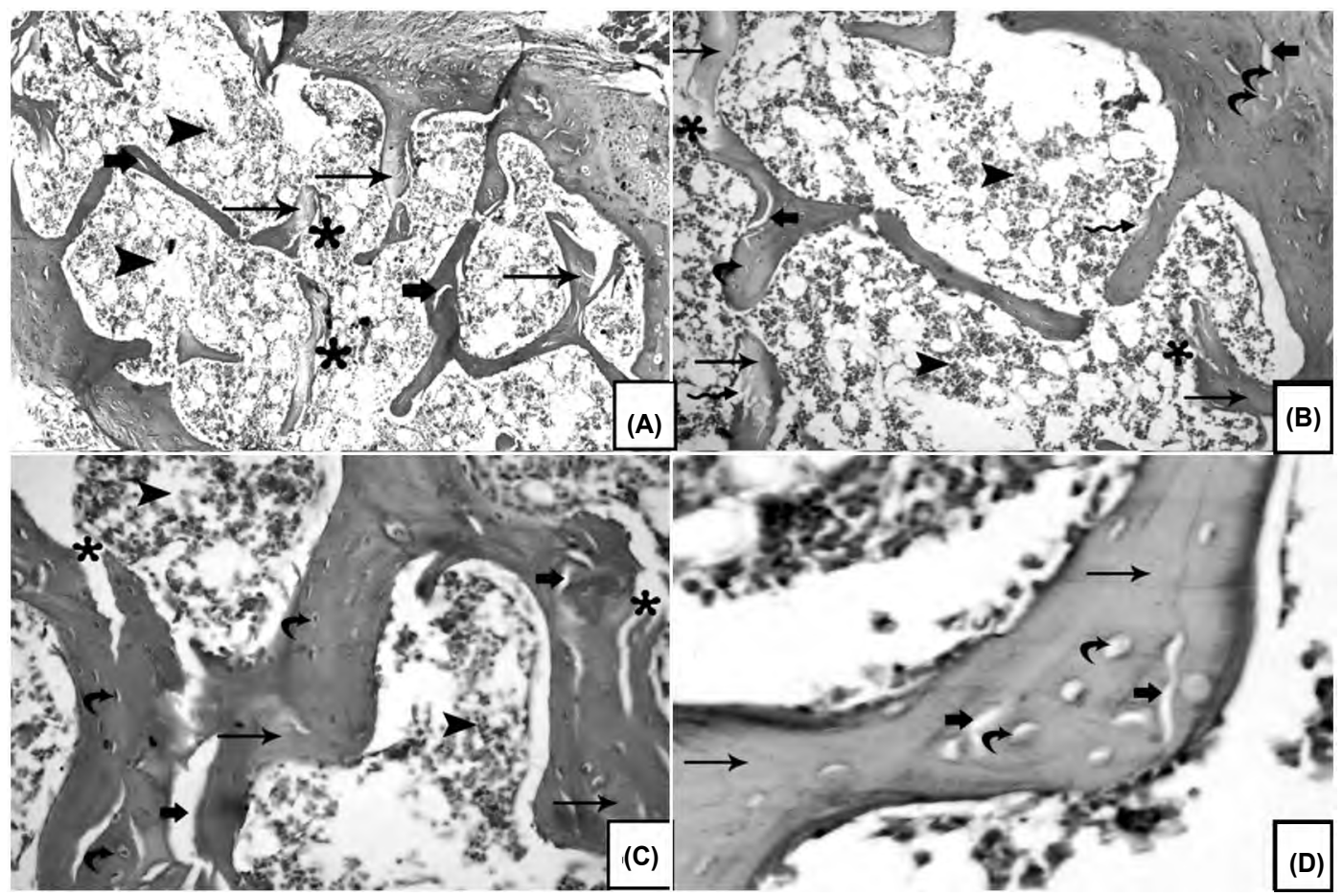

Fig. (2): A photomicrograph of a rat head of femur of Group III (osteoporosis induced group) showing discontinuous thin cancellous bone trabeculae having blind ends and areas of apparent faintly stained matrix (arrows) together with minor fractures (asterisks) and multiple pores (wide short arrows). Wide bone marrow spaces are seen between the trabeculae containing less haemopoietic cells and abundant adipocytes (arrow heads). Notice, endosteum shows irregular eroded surface (wavy arrows) and some osteocytes inside their apparently large lacunae while other lacunae appear without osteocytes (curved arrow) (H \& E, 2A, X100, 2B X200, 2C X400 \& 2D X1000).

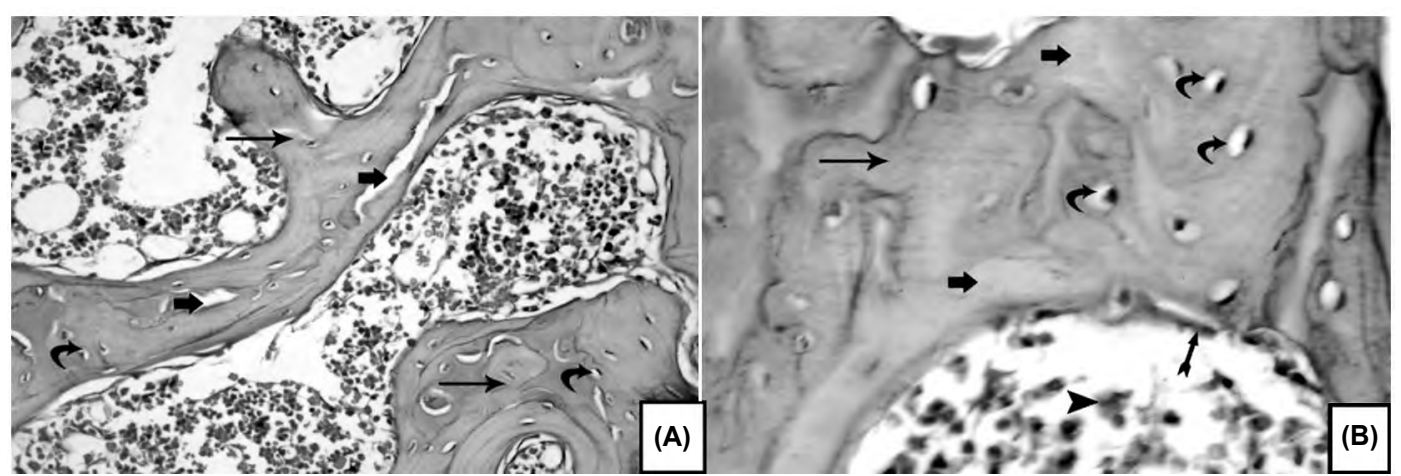

Fig. (3): A photomicrograph of a rat head of femur of Group IV (prednisolone + lycopene group) showing network of relatively thin trabeculae of cancellous bone (arrows) having faintly stained areas or small pores (wide short arrows) and apparent increased osteocytes inside their lacunae (curved arrows). Notice, the regular continuous endosteal surface (bifid arrow) lining the bone marrow cavity (arrow head) (H \& E, 3A, X400 \& 3B X1000).

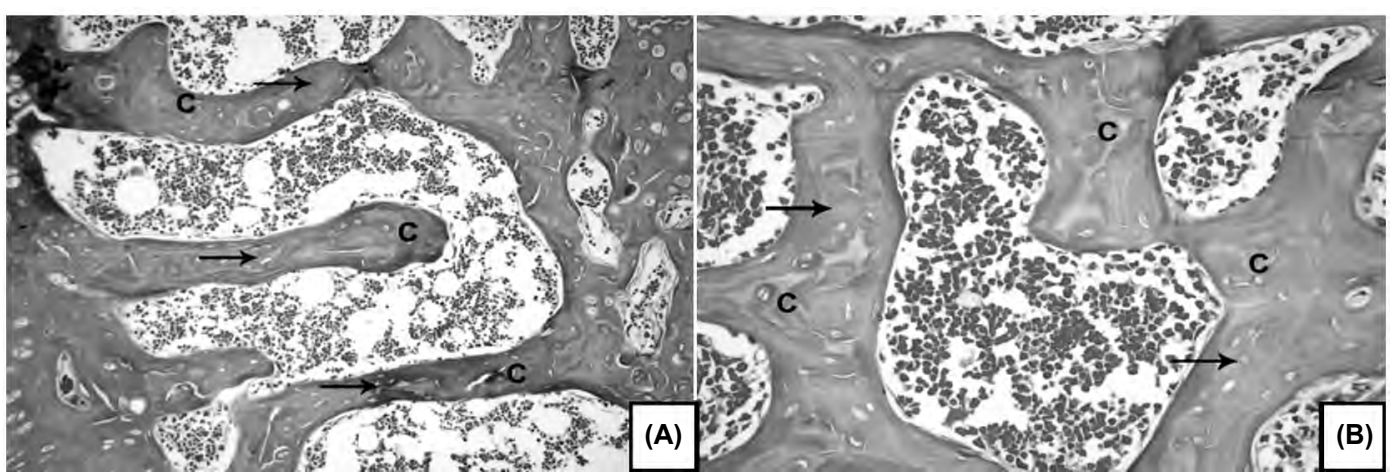

Fig. (4): A photomicrograph of a control rat head of femur showing anastomosing thick network of trabeculae of cancellous bone (arrows). Collagen fibers exhibited by blue coloration of bone matrix (C) (Mallory trichrome stain, 4A, $\mathrm{X} 200$ \& 4B X400). 
Group III: Examination of sections obtained from the head of femur of this group revealed irregular distribution of collagen fibers and apparent decrease in their contents as exhibited by faint blue coloration of bone matrix Fig. (5A,B).

Group IV: Examination of sections obtained from the head of femur of this group showed relatively less changes as compared to Group III (osteoporosis induced group). There was irregular distribution of collagen fibers of bone matrix as exhibited by intensity of the blue coloration. Their content was observed to be apparently less than control group but more than that was observed in Group III Fig. (6A,B).

\section{II- Scanning electron microscopic results:}

Group I: Examination of scanning electron microscopic specimens obtained from the head of femur of both subgroups I-A \& I-B showed anas- tomosing thick network of cancellous bone trabeculae containing lacunae of osteocytes. Bone marrow spaces were seen between trabeculae lined by smooth regular endosteal surfaces Fig. (7A-D).

Group II: Examination of scanning electron microscopic specimens obtained from the head of femur of this group revealed nearly the same histological picture as in the control group.

Group III: Examination of scanning electron microscopic specimens obtained from the head of femur of this group revealed changes of different degrees of osteoporosis. These changes were in the form of discontinuous, thin and blind ended cancellous bone trabeculae containing areas of decreased electron density with multiple pores and minor fissures and fractures. Wide bone marrow spaces were seen between trabeculae lined with irregular eroded endosteal surface Fig. (8A-D).

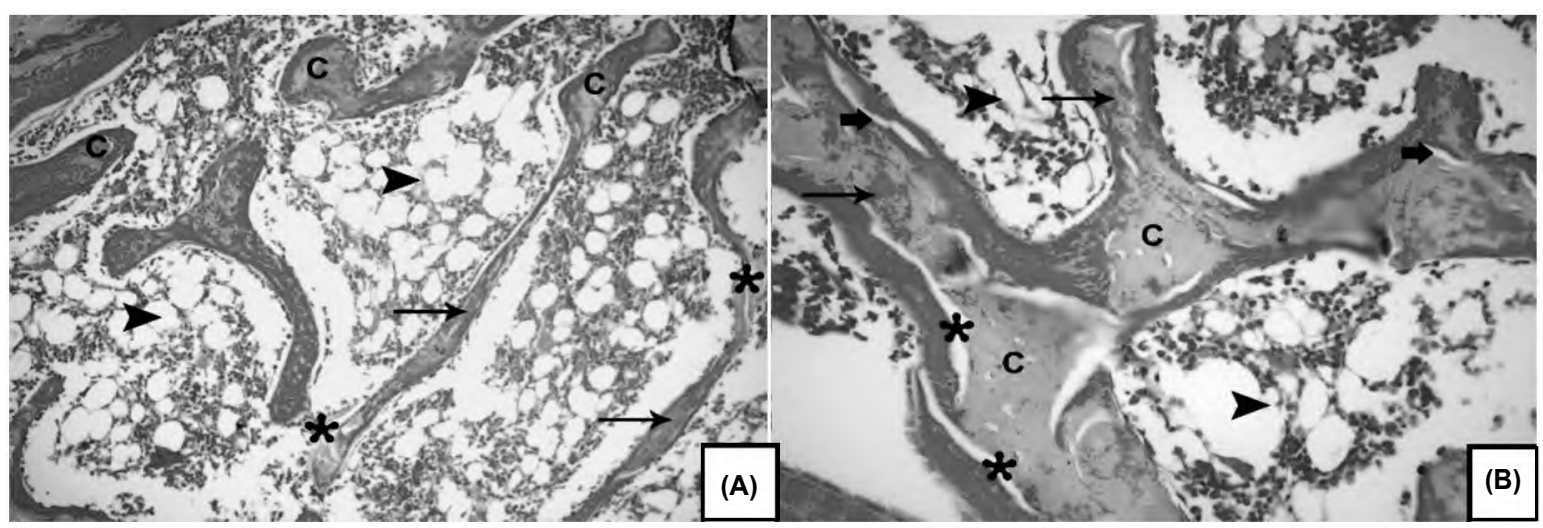

Fig. (5): A photomicrograph of a rat head of femur of Group III (osteoporosis induced group) showing discontinuous thin trabeculae of cancellous bone with blind ends (arrows) with irregular distribution of collagen fibers and decreased their contents exhibited by faint blue coloration of bone matrix (C). Notice, minor fractures (asterisks) with multiple pores inside the trabeculae (wide short arrows) and wide bone marrow spaces in-between containing abundant adipocytes (arrow heads). (Mallory trichrome stain, 5A, X200 \& 5B X400).
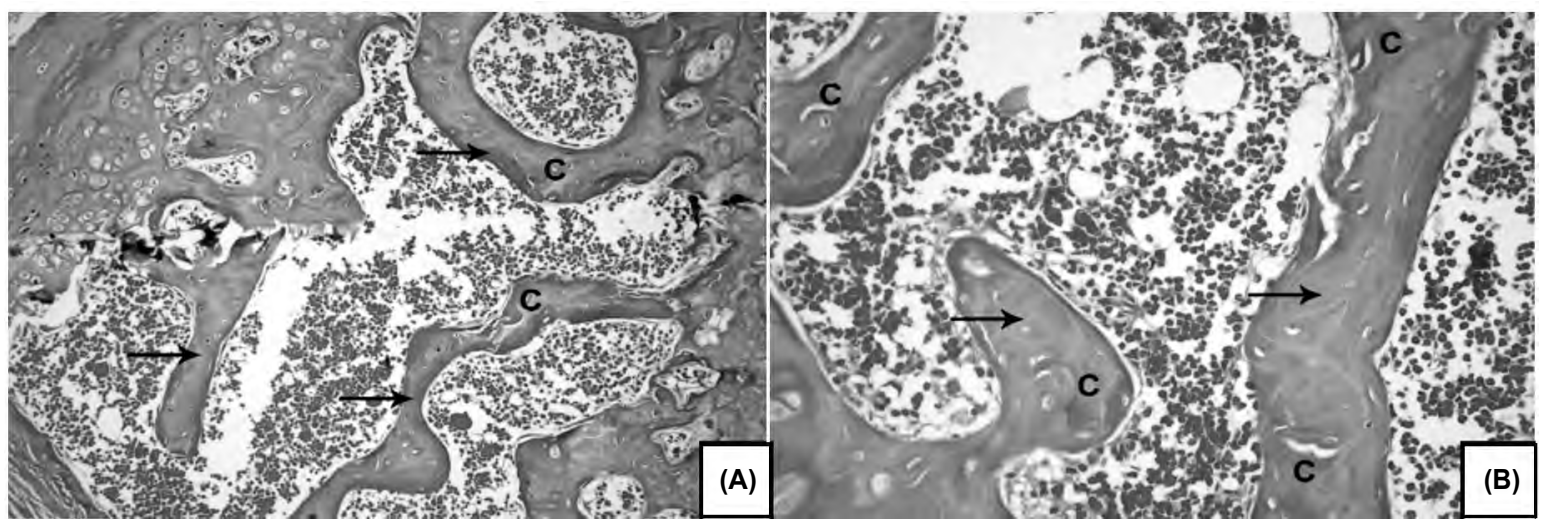

Fig. (6): A photomicrograph of a rat head of femur of Group IV (prednisolone + lycopene group) showing network of relatively thin trabeculae of cancellous bone (arrows) with irregular distribution of collagen fibers and their contents appear less than normal but more than that of Group III as exhibited by blue coloration of bone matrix (C) (Mallory trichrome stain, 6A, X200 \& 6B X400). 


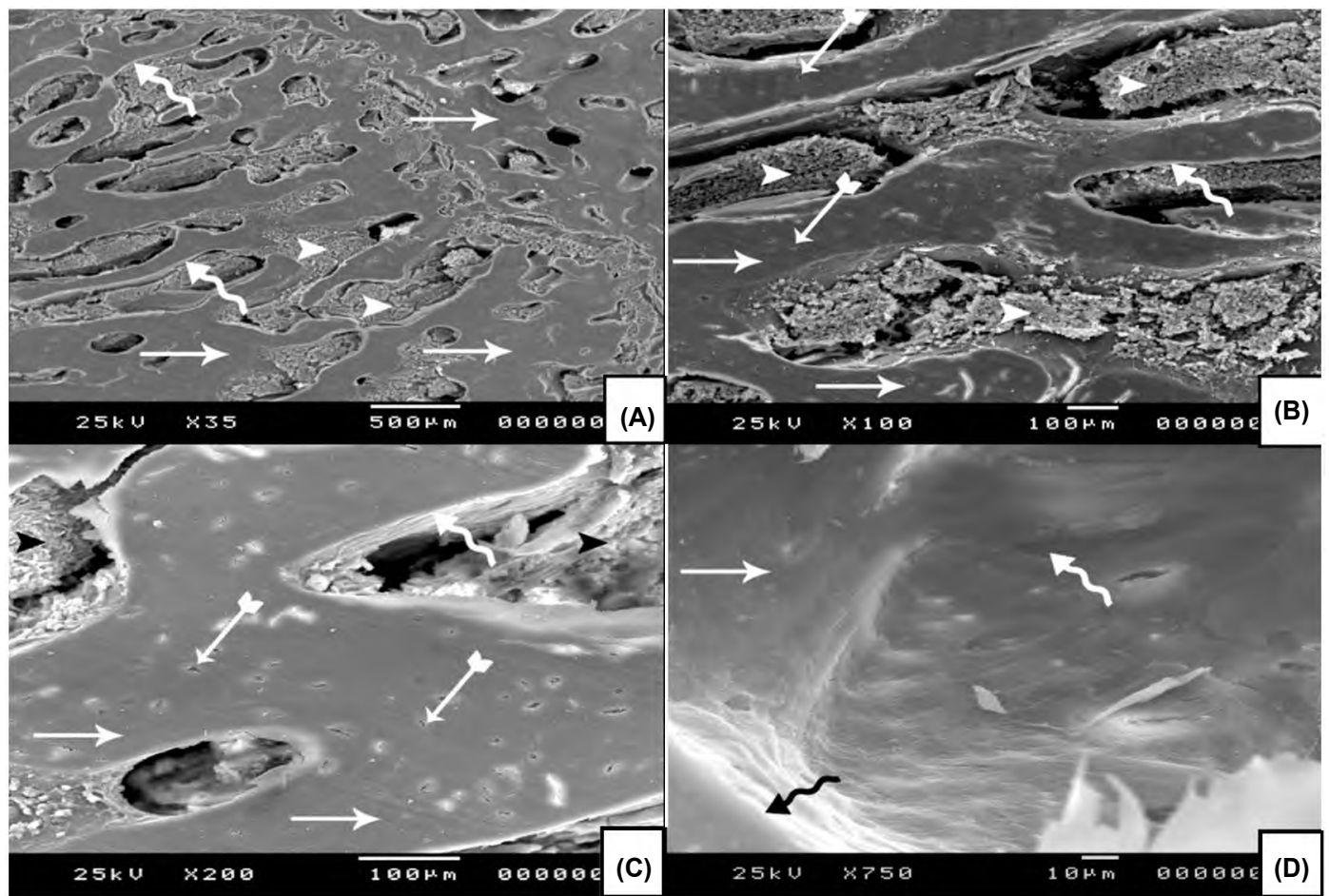

Fig. (7): A scanning electron micrograph of a control rat head of femur showing anastomosing thick network of cancellous bone trabeculae (arrows) containing lacunae of osteocytes (bifid arrows). Bone marrow spaces (arrow heads) are lined by smooth regular endosteal surface (wavy arrows) (Scanning EM 7A, X35, 7B X100, 7C X200 \& 7D X750).

Group IV: Examination of scanning electron microscopic specimens obtained from the head of femur of this group revealed relatively thin trabeculae of cancellous bone as compared to control group, containing lacunae of osteocytes. Occasion- ally, fissures and pores were observed in few trabeculae. Bone marrow spaces were seen between trabeculae, their lining endosteal surfaces were smooth with focal areas of irregularity Fig. (9AD).

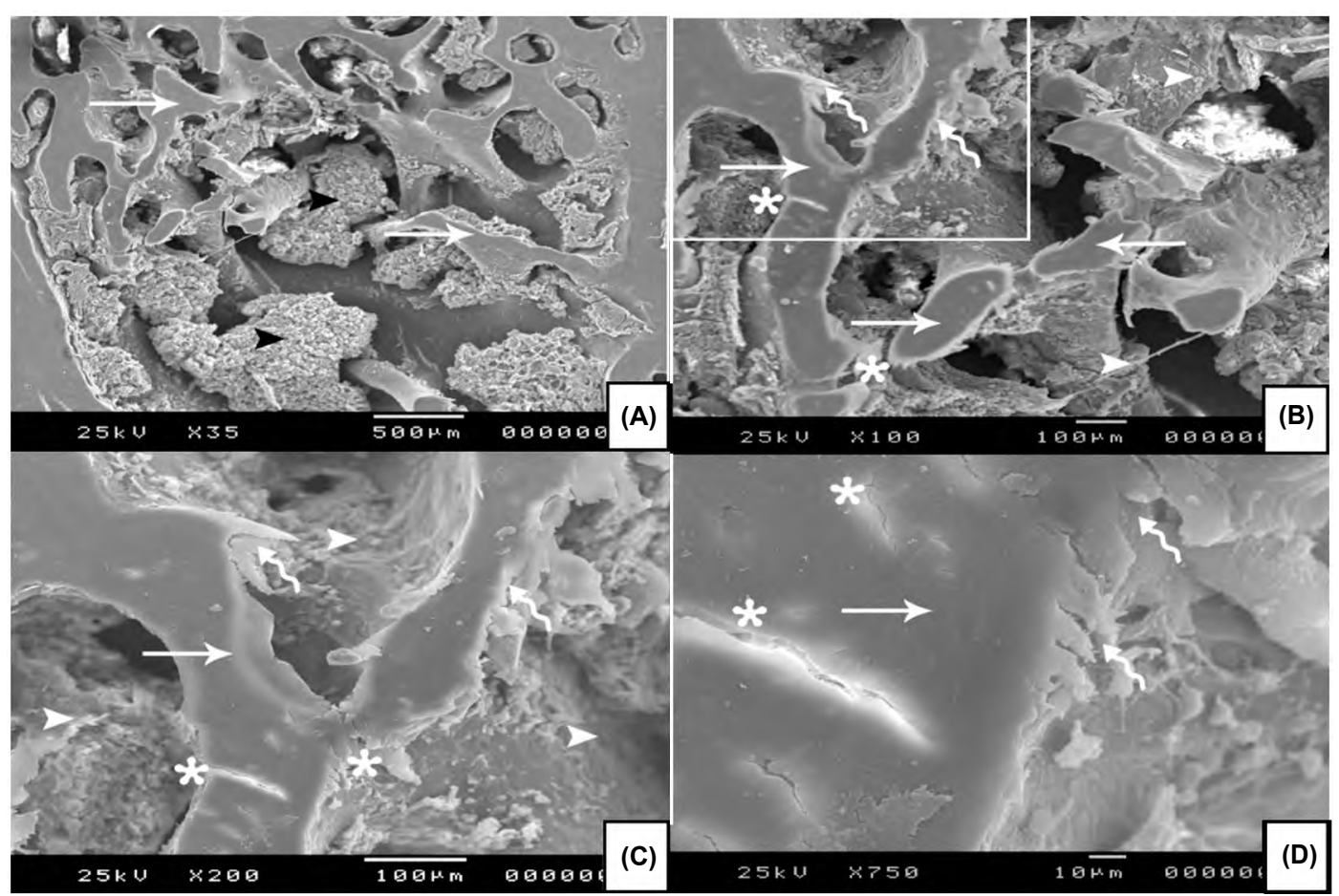

Fig. (8): A scanning electron micrograph of a rat head of femur of Group III (osteoporosis induced group) showing discontinuous thin and less electron dense cancellous bone trabeculae with blind ends (arrows) containing minor fissures and fractures (asterisks). Wide interconnected bone marrow spaces are seen between trabeculae (arrow heads) are lined by irregular eroded endosteal surface (wavy arrows). (Scanning EM 8A, X35, 8B X100, 8C X200 \& 8D X750). 


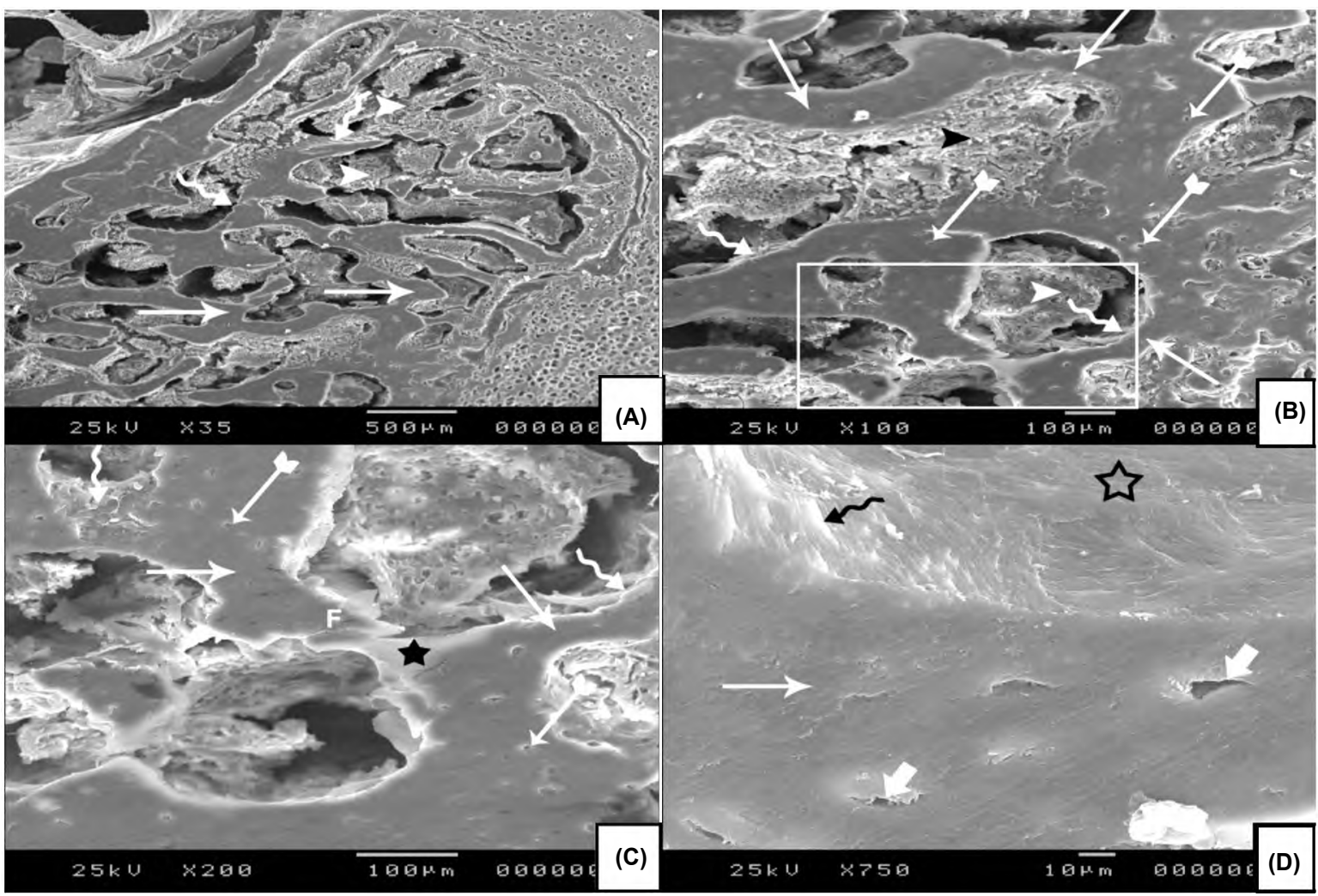

Fig. (9): A scanning electron micrograph of rat head of femur of Group IV (prednisolone + lycopene group) showing network of relatively thin trabeculae of cancellous bone (arrows) containing many lacunae of osteocytes (bifid arrows). Bone marrow spaces (arrow heads) are lined by smooth endosteal surface with focal areas of irregularity (wavy arrows). Notice in 9C, the area having less electron density (star) and the fissure inside bone trabeculae (F). Also Notice in 9D, cancellous bone trabecula containing some pores (wide short arrows) and its endosteal surface is smooth (empty star) with area of irregularity (wavy arrow) (Scanning EM 9A, X35, 9B X100, 9C X200 \& 9D X750).

\section{Quantitative assessment and statistical analysis:}

Evaluation of collagen fiber contents in Mallory's trichrome stained sections:

Statistical analysis of the data collected by the image analysis software program (Image $\mathrm{J}$, version $1.48)$ revealed that there was no significant difference ( $p$-value $>0.05)$ in the mean area percentage of collagen fiber contents of sections from the head of femur of Group II and Group IV as compared to control group. But Group III (osteoporosis induced group) showed statistically highly significant decrease $(p$-value $<0.001)$ in the mean area percentage of collagen fiber contents as compared to control group. Also, Group III showed statistically highly significant decrease ( $p$-value $<0.001)$ in the mean area percentage of collagen fiber contents as compared to Group IV (protective group). All these data are illustrated in (Tables 1,2) and Histogram (1).
Table (1): The mean area percentage of collagen fiber contents in different studied groups (ANOVA test).

\begin{tabular}{|c|c|c|c|c|}
\hline \multirow{2}{*}{ Groups } & \multicolumn{2}{|c|}{$\begin{array}{l}\text { Area percentage of } \\
\text { collagen fiber contents }\end{array}$} & \multicolumn{2}{|c|}{ ANOVA } \\
\hline & Range & Mean \pm SD & $\mathrm{F}$ & $p$-value \\
\hline I- Control & $26.363-37.263$ & $31.207 \pm 3.584$ & 29.974 & $<0.001 *$ \\
\hline II- Lycopene & $26.227-39.911$ & $32.412 \pm 4.676$ & & \\
\hline III- Prednisolone & $9.055-22.537$ & $16.549 \pm 4.196$ & & \\
\hline $\begin{array}{l}\text { IV- Lycopene }+ \\
\text { Prednisolone }\end{array}$ & $23.777-37.507$ & $30.003 \pm 4.545$ & & \\
\hline
\end{tabular}

Table (2): The mean area percentage of collagen fiber contents in different studied groups (Tukey's test).

\begin{tabular}{llllll}
\hline \multicolumn{5}{c}{ TUKEY'S Test } \\
\hline I \& II & I \& III & I \& IV & II \&III & II \&IV & III \&IV \\
\hline$>0.05$ & $<0.001 *$ & $>0.05$ & $<0.001 *$ & $>0.05$ & $<0.001^{*}$ \\
\hline
\end{tabular}

SD: Standard Deviation.

$p$-value $>0.05$ : Non-significant.

$p$-value $<0.001(*)$ : Highly significant. 


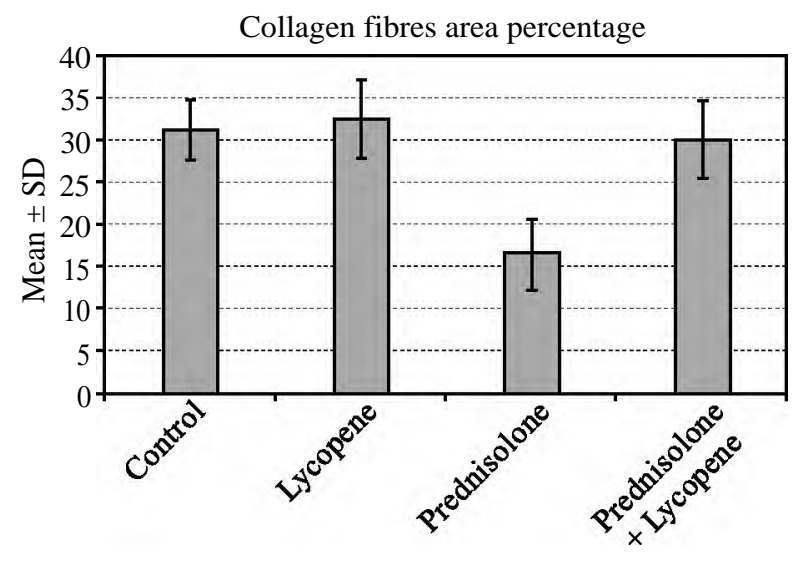

Histogram (1): Comparison between groups as regard means of area percentage the collagen fiber contents in head of femur in different studied groups.

\section{Discussion}

Our study was done to evaluate the possible protective effects of lycopene against glucocorticoid-induced osteoporosis in adult male albino rat.

The head of femur was chosen in this work to evaluate the changes in cancellous bone trabeculae because it is the most sensitive part to the effect of glucocorticoid treatment on GIOP [18]. Meanwhile, Kumar et al., [19] stated that trabecular bone is usually affected more severely than cortical bone because of its greater metabolic activity.

The microscopic examination of haematoxylin $\&$ eosin stained sections of the femur head, in the osteoporosis induced group showed changes in the form of discontinuous thin trabeculae of cancellous bone with focal areas of apparent faintly stained matrix with multiple pores inside trabeculae. There were blind ends of trabeculae associated with minor fissures and fractures. Wide bone marrow spaces were seen between trabeculae containing less hemopoietic cells and abundant adipocytes than the control group. The endosteum surface appeared irregular and eroded. In addition, osteocytes inside their apparently large lacunae and some empty lacunae were detected.

Examination of Mallory trichrome stained sections obtained from the femur head of this group showed irregular distribution of collagen fibers and decrease their contents exhibited by faint blue coloration of bone matrix. Statistical analysis of the data collected by the image analysis software program revealed that there was statistically highly significant decrease $(p$-value $<0.001)$ in the mean area percentage of collagen fiber contents of sections from the head of femur of this group as compared to control group.
Scanning electron microscope was chosen in our study to distinguish various bone surface activity status and detect variations in mineralized tissue matrix properties [20,21]. Specimens examined by SEM revealed discontinuous, thin and blind ended cancellous bone trabeculae containing some areas of decreased electron density with multiple pores and minor fissures and fractures inside them. Wide bone marrow spaces were seen between trabeculae lined with irregular eroded endosteal surface.

Therefore, the present study revealed the evidence of prednisolone induced osteoporosis, demonstrated by light and scanning electron microscopes which was identical to what is described by the histopathologists Matthew \& Laura [22], who stated that the hallmark of osteoporosis is a reduced bone mass leading to trabecular thinning and perforation resulting in progressive microfractures. Also, it leads to reduction of the trabecular network connectivity and more widely separated than usual.

Yao et al., [23] described that glucocorticoids in animal models impact trabecular bone first, result in significant reductions in its volume and whole bone strength. Similar finding was found by Barbara et al., [24], who reported that with prolonged use of glucocorticoid there is reduction of mean wall thickness of trabecular bone packets, with a consequent decrease in total bone volume. This explain the thin trabeculae with eroded surfaces seen in the present study.

Many previous researches explained the mechanism by which glucocorticoid induced osteoporosis. Goulding and Flower [25] reported glucocorticoids inhibit intestinal absorption of calcium causing secondary hyperparathyroidism, in turn, stimulates osteoclasts to increase bone resorption. In addition, steroid drugs directly inhibit the activity of osteoblasts and stimulate the urinary excretion of both calcium and phosphorus.

The large lacunae seen in the present study were previously explained by Lane et al., [26], who studied glucocorticoid treatment in animal models as a direct effect on osteocytes, resulting in a modification of their microenvironment and the generation of surrounding areas of hypomineralized bone around the lacunae with a reduction of mineral-to-matrix content.

Glucocorticoid induced osteoporosis results from variation in bone turnover. It increases resorption by increasing osteoclast lifespan and 
decreases formation by inducing osteoblast and osteocyte apoptosis, that explain the presence of some empty lacunae [27]. In addition, glucocorticoid inhibits the differentiation of mesenchymal precursor cells into osteoblasts by directing the precursors toward adipocyte development, which explains the presence of more adipocytes in bone marrow spaces in osteoporosis group of the present study [28] .

During the remodeling process, osteoblasts and osteoclasts interact with multiple molecular agents including hormones, growth factors, and cytokines. Metabolic bone diseases such as osteoporosis result from disturbances in the remodeling process [29] Moreover, Preedy and Watson [30] reported that osteoporosis is in part due to the actions of oxidative stress on both osteoclasts and osteoblasts; antioxidants counteract these actions. This goes in line with Callaway and Jiang [31], who stated that Reactive Oxygen Species (ROS) may be a key player in the pathogenesis of different pathological conditions, such as osteoporosis, with established positive correlations between the presence of excessive ROS and bone loss. Altindag et al., [32] added that antioxidant supplementation has been proposed as a novel therapeutic strategy in this disease. This was in agreement with Rao et al., [33], who explained that under normal physiological conditions, oxidative stress can be prevented by promoting antioxidant defenses. Exogenous antioxidants from dietary sources present in fruit and vegetables are also utilized to combat oxidative stress.

Although the severity and consequence of glucocorticoid-induced osteoporosis, it is preventable, treatable and potentially reversible. The prevention and treatment of GIOP include some general measures, calcium and vitamin D supplementation and treatment with bone anabolic and antiresorptive agents as bisphosphonates [34]. In addition, there is an increasing demand for complementary and alternative medicine for the prevention and treatment of osteoporosis due to the adverse side effects of hormonal therapy and the bisphosphonates in the management of osteoporosis; these include diet, exercise, and nutritional supplements. Recent trials of antioxidant supplementation are an effective therapeutic tool in the prevention of GCinduced bone damage [35]

In the present study, co-administration of lycopene minimized the structural changes induced by prednisolone together with preservation of the normal histological structure which was variable from animal to animal. However, there were relatively thin trabeculae of cancellous bone and wide bone marrow spaces were seen between trabeculae. Few small pores inside trabeculae and apparent more osteocytes inside their lacunae were observed. Mallory trichrome stained sections, they showed relative preservation of collagen fibers content as exhibited by blue coloration of bone matrix. Statistical analysis of the data collected by the image analysis software program revealed that there was no significant difference ( $p$-value $>0.05$ ) in the mean area percentage of collagen fiber contents of sections from the head of femur of this group as compared to control group.

Examination of scanning electron microscopic specimens of protective group confirmed the results obtained by the light microscope and revealed many lacunae of osteocytes inside the thin trabeculae of cancellous bone. Occasionally, some fissures and pores were observed in few trabeculae. The lining endosteal surfaces of the bone marrow spaces were smooth with focal areas of irregularity.

Plant derivatives such as lycopene from tomato extract is a natural antioxidant helping in contrasting the progress of some pathological events whose origin resides in the generation of free radicals [36]. The protective effect of lycopene can be attributed according to epidemiological studies of Sahni et al., [37], who demonstrated the role of lycopene as an antioxidant in the prevention of oxidative stress-related osteoporosis and correlation with bone mineral density in postmenopausal women. This goes in line with Mackinnon et al., [6], who stated the role of lycopene in reduction either oxidative stress or levels of bone turnover markers in postmenopausal women, thus resulting potentially beneficial in reducing the risk of osteoporosis.

It was found that lycopene has stimulating effect on osteoblast cell proliferation as well as a stimulatory effect on alkaline phosphatase activity in human osteoblast [38] . It is also able to prevent and repair the damaging effects of oxidative stress. Also, Yang et al., [39], claimed that lycopene may shift the bone metabolic equilibrium towards an increase in the anabolic state leading to decrease in bone resorption levels in osteoporosis.

The effects of lycopene on osteoclasts have been also reported by Krishnadev et al., [40], who demonstrated that lycopene can inhibit multinucleated osteoclast cell formation as well as the formation of ROS-secreting osteoclasts in bone marrow cells from rat femur. The protective role of lycopene in human disorders such as osteoporosis may be due to its ability to suppress biomarkers of oxidative stress which play important role of the pathogenesis 
of osteoporosis, because oxidative stress controls the functions of both osteoclasts and osteoblasts [41].

The protective role of lycopene according to Batra et al., [42] could be attributed to the involvement of other important processes such as stimulation of gap junction communications, induction of the production of detoxifying enzymes leading to modulation of cell cycle and apoptosis. Since intercellular communications through gap junctions are key events of normal osteoclast and osteoblast metabolism, consequently, on bone remodeling. Lycopene may modulate gap junction communication to suggest that this may also represent a potentially target of action of lycopene on bone cells.

It was observed that lycopene, at levels found in plasma after the ingestion of lycopene-containing products, leading to decrease osteoclast differentiation, but did not affect cell density/survival; calcium-phosphate resorbing ability was also decreased. On the other hand, osteoblast proliferation (via a decrease on apoptosis) and differentiation was increased in the presence of lycopene which may contribute to the promotion of a proper health status of bone tissue. They concluded that, the previous information might be relevant for the prevention and delay in the progression of osteolytic bone conditions [43]

Furthermore, Iimura et al., [44] showed that lycopene intake by ovariectomized rats facilitates the increase of bone mineral density and bone strength. This was in consistent with Ardawi et al., [45], who stated that, in an ovariectomized mice model, lycopene can help against the loss of bone mass, that primarily suppressed bone turnover to restore bone strength and microarchitecture, improving bone biomechanical properties with an increase in both antioxidant enzyme activity and osteoblast activity.

Lycopene can be used either as a dietary alternative or as a complement to the pharmaceuticals used in the form of capsules $30-70 \mathrm{mg} /$ day to exert equivalent antioxidant potency in reducing the risk of osteoporosis in postmenopausal women [46] Similar finding was reported by Jiuhong et al., [47] based on the evidence from observational studies, meta-analysis supported the hypothesis that higher dietary total carotenoids intake might be potentially associated with a low risk of hip fracture.

On the other hand, it was found a non-significant association between serum lycopene and hip fracture risk among elderly women [48]. Furthermore,
Wolf et al., [49] reported that there is no significant protective association at any bone mineral density site with serum carotenoids. Sahni et al., [50] also showed a null association of dietary lycopene with hip fracture risk among women.

\section{Conclusion:}

Based on the current study and from all previously mentioned histological and statistical results, it could be concluded that the osteoporosis resulted from administration of glucocorticoids in adult male albino rats can be partially minimized by lycopene co-administration. So, it is recommended that lycopene can be used as a dietary alternative to drug therapy or as a supplement to people at risk for osteoporosis.

\section{References}

1- JOHNELL O., KANIS J.A., ODEN A., SERNBO I., REDLUND-JOHNELL I. and PETTERSON C.: "Mortality after osteoporotic fractures." Osteoporosis. Int., 15 (1): 38-42, 2004.

2- ANDRÉ V., Le GOFF B. and LEUX C.: "Information on glucocorticoid therapy in the main studies of biological agents." Joint Bone Spine, 78: 478-83, 2001.

3- CANALIS E. and DELANY A.M.: "Mechanisms of glucocorticoid action in bone." Ann. N. Y. Acad. Sci., 966: 73-81, 2002.

4- LIN S., HUANG J., ZHENG L., LIU Y., LIU G., LI N., WANG K., ZOU L., WU T., QIN L., CUI L. and LI G.: "Glucocorticoid-induced osteoporosis in growing rats." Calcif Tissue Int., 95 (4): 362-73, 2014.

5- AGARWAL S. and RAO A.V.: "Tomato lycopene and its role in human health and chronic diseases." CMAJ, 163 : 739-44, 2000

6- MACKINNON E.S., RAO A.V. and RAO L.G.: "Dietary restriction of lycopene for a period of one month resulted in significantly increased biomarkers of oxidative stress and bone resorption in postmenopausal women." J. Nutr. Health Aging., 15: 133-8, 2011.

7- HAIDONG L., FANG Y., ZHIHONG T. and WEIFENG Z.: "Lycopene effects on serum mineral elements and bone strength in rats." Molecules, 17: 7093-102, 2012.

8- National Research Council of the National Academies: "Guide for Care and Use of the Laboratory Animals", 8 th edition, The National Academies Press, Washington, USA. Chapter 3, Environment, housing and management, P: 41-104, 2011.

9- OGOSHI T., HAGINO H., FUKATA S., TANISHIMA S., OKANO T. and TESHIMA R.: "Influence of glucocorticoid on bone in 3, 6 and 12 month-old rats as determined by bone mass and histomorphometry." Mod. Rheumatol., 18 (6): 552-61, 2008.

10- KALLENY N.: "Histological and morphometric studies on the effect of alpha-lipoic acid on postovariectomy osteoporosis induced in adult female albino rats." The Egyptian Journal of Histology, 34: 139-55, 2011. 
11- AVMA (American Veterinary Medical Association): "Guidelines for the euthanasia of animals", 2013.

12- DRURY R.B. and WALLINGTON E.A.: "Carleton's Histological Technique", $5 \mathrm{t}^{\mathrm{h}}$ edition, Oxford University Press. Chapter 7, Methods for special organs, tissues, and cell components, P: 179-84, 1980.

13-BANCROFT J.D., CHRISTOPHE L. and KIM S.: "Bonein Bancroft's Theory and Practice of Histological Techniques", 7 th edition, Churchill Livingstone, China. Chapter 16, P: 323-28, 2013.

14- BANCROFT J.D. and GAMBLE M.: "Connective tissue and stain. In Theory and Practice of Histological Techniques", 5 th edition, Churchill Livingstone, London, Sydney, New York, Toronto, p. 135-60, 2002.

15- WEESNER A.: "Mallory triple stain in General Zoological microtechniques." Scientific book Agency Calcutta, p. 88, 1968.

16- BELL L.S.: "Forensic Microscopy for Skeletal Tissues", Methods and Protocols, Humana Press Springer Science+Business Media, LLC. Chapter 1, Scanning electron microscopy: Preparation and imaging for SEM, p. 1-20, 2012.

17- HELFRICH M.H. and RALSTON S.H.: "Bone Research Protocols", 2 nd edition, Humana press Springer Science + Business Media, LLC. Chapter 24, Scanning electron microscopy of bone, p. 365-400, 2012.

18- GIUSTI A., HAMDY N.A. and PAPAPOULOS S.E.: "Atypical fractures of the femur and bisphosphonate therapy: A systematic review of case/case series studies." Bone, 47: 169-80, 2010.

19- KUMAR V., ABBAS A. and ASTER J.: "Robbins Basic Pathology", 10th edition, Elsevier Inc. Chapter 21, Bone, joint, soft tissue tumor, p. 797-831, 2017.

20- BOYDE A. and JONES S.J.: "Scanning electron microscopy of bone: Instrument, specimen and issues." Microscopy Research and Technique, 33: 92-120, 1996.

21- HOWELL P.G. and BOYDE A.: "Volumes from which calcium and phosphorus X-rays arise in electron probe emission microanalysis of bone: Monte Carlo simulation." Calcif. Tissue Int., 72: 745-49, 2003.

22- MATTHEW R.L. and LAURA W.L.: "Diagnostic Pathology: Normal Histology", ${ }^{2 n d}$ edition, Elsevier. Chapter 12, Bone and cartilage, p. 58-65, 2018.

23- YAO W., CHENG Z. and BUSSE C.: "Glucocorticoid excess in mice results in early activation of osteoclastogenesis and adipogenesis and prolonged suppression of osteogenesis: A longitudinal study of gene expression in bone tissue from glucocorticoid-treated mice." Arthritis Rheum., 58: 1674-86, 2008.

24- BARBARA P., LUKERT B.P. and RAISZ L.G.: "Glucocorticoid-induced osteoporosis: Pathogenesis and management." Annals of Internal Medicine, 112 (5): 352-64, 1990.

25- GOULDING N.J. and FLOWER R.J.: "Glucocorticoids Milestones in Drug Therapy", Springer Basel AG. Chapter 3, The development of synthetic glucocorticoids, P: 35$51,2001$.

26- LANE N.E., YAO W. and BALOOCH M.: "Glucocorticoidtreated mice have localized changes in trabecular bone material properties and osteocyte lacunar size that are not observed in placebo-treated or estrogen-deficient mice." J. Bone Miner. Res., 21: 466-76, 2006.

27- WALSH J.S.: "Normal bone physiology, remodeling and its hormonal regulation." Basic Science, p. 2-6, 2014.

28- FENG M., ZHANG R., GONG F., YANG P., FAN L., NI J., BI W., ZHANG Y., WANG C. and WANG K.: "Protective effects of necrostatin-1 on glucocorticoid-induced osteoporosis in rats." J. Steroid. Biochem. Mol. Biol., 144: 455-62, 2014

29- LERNER U.H.: "Bone remodeling in post-menopausal osteoporosis." J. Dent. Res., 85: 584-95, 2016.

30- PREEDY V.R. and WATSON R.R.: "Lycopene Nutritional, Medicinal and Therapeutic Properties", Science Publishers. Chapter 1, Characterization of lycopene from chemistry to basic physiological functions. p. 2-17; Chapter 2, Stability of lycopene during food processing and storage. p. 17-37; Chapter 5, risk assessment of lycopene. p. 83101; Chapter 10, lycopene and bone tissue. p. 309-26, 2009.

31- CALLAWAY D.A. and JIANG J.X.: "Reactive oxygen species and oxidative stress in osteoclastogenesis, skeletal aging and bone diseases." J. Bone Miner. Metab., 33: 359-70, 2015

32- ALTINDAG O., EREL O., SORAN N., CELIK H. and SELEK S.: "Total oxidative/anti-oxidative status and relation to bone mineral density in osteoporosis." Rheumatol. Int., 28: 317-21, 2008.

33- RAO V., YOUNG G.L. and RAO L.: "Lycopene and Tomatoes in Human Nutrition and Health", Taylor \& Francis Group, LLC. Chapter 1, Lycopene. P: 1-21, Chapter 4, Lycopene, tomatoes, and cardiovascular diseases, p. 51-68, 2018.

34- MANELLI F. and GIUSTINA A.: "Glucocorticoid-Induced Osteoporosis", Elsevier Science Ltd., 11 (3): 79-85, 2000.

35- REES M.: "Management of the menopause: Integrated health-care pathway for the menopausal woman." Menopause Int., 17: 50-4, 2011.

36- SGHERRI C., PINZINO C., NAVARI-IZZO F., IZZO R. and QUARTACCI M.F.: "Antioxidant potential in lipophilic and hydrophilic extracts from medicinal herbs. A comparison between assays based on electron paramagnetic resonance and spectrophotometry." American Journal of Agricultural and Biological Sciences, 7: 417-24, 2012.

37- SAHNI S., HANNAN M., BLUMBERG J., CUPPLES L., KIEL D. and TUCKER K.: "Protective effect of total carotenoid and lycopene intake on the risk of hip fracture: A 17-year follow-up from the Framingham Osteoporosis Study." J. Bone Miner. Res., 24: 1086-94, 2009.

38- KIM L., RAO A.V. and RAO L.G.: "Lycopene II. Effect on osteoblasts: The carotenoid lycopene stimulates cell proliferation and alkaline phosphatase activity of SaOS2 cells." J. Med. Food, 6 (2): 79-88, 2004.

39- YANG Z., ZHANG Z., PENNISTON K.L., BINKLEY N. and TANUMIHARDJO S.A.: "Serum carotenoid concentrations in postmenopausal women from the United States with and without osteoporosis." Int. J. Vitam. Nutr. Res., 78: 105-11, 2008.

40- KRISHNADEV N., BANASIKOWSKA K. and RAO A.V.: "Lycopene I. effect on osteoclasts; lycopene inhibits 
basal and parathyroid hormone (PTH)-stimulated osteoclast formation and mineral resorption mediated by reactive oxygen species (ROS) in rat bone marrow cultures." J. Med. Food, 6: 69-78, 2003.

41- RAO L.G.: "Tomato lycopene and bone health: Preventing osteoporosis. In: Rao AV, editor. Tomatoes, lycopene and human health." Scotland: Caledonian Science Press, p. 153-68, 2006.

42- BATRA N., KAR R. and JIANG J.X.: "Gap junctions and hemichannels in signal transmission, function and development of bone." Biochim. Biophys. Acta, 1818: 1909-18, 2012.

43- COSTA-RODRIGUES J., FERNANDES M.H., PINHO O. and MONTEIRO P.R.: "Modulation of human osteoclastogenesis and osteoblastogenesis by lycopene." The Journal of Nutritional Biochemistry, 57: 26-34, 2018.

44- IIMURA Y., AGATA U., TAKEDA S., KOBAYASHI Y., YOSHIDA S., EZAWA I. and OMI N.: "The protective effect of lycopene intake on bone loss in ovariectomized rats." J. Bone Miner. Metab., 33: 270-78, 2015.

45- ARDAWI M.S., BADAWOUD M.H., HASSAN S.M., ALNOSANI N.M., QARI M.H. and MOUSA S.A.: "Lycopene treatment against loss of bone mass, microarchitecture and strength in relation to regulatory mechanisms in a postmenopausal osteoporosis model." Bone, 83: 127 40, 2016.

46- MACKINNON E.S., RAO A.V., JOSSE R. and RAO L.: "Supplementation with the antioxidant lycopene significantly decreases oxidative stress parameters and the bone resorption marker $\mathrm{N}$-telopeptide of type I collagen in postmenopausal women." Osteoporosis Int., 22: 1091101, 2011.

47- JIUHONG X., CHUNLI S., XIAOCHAO S., ZHANG X and XINLI L.: "Carotenoids and risk of fracture: A metaanalysis of observational studies." Oncotarget, 8 (2): 2391-9, 2017

48- BARKER M.E., McCLOSKEY E., SAHA S., GOSSIEL F., CHARLES WORTH D., POWERS H.J. and BLUMSOHN A.: "Serum retinoids and 3 -carotene as predictors of hip and other fractures in elderly women." Journal of Bone and Mineral Research, 20: 913-20, 2005.

49- WOLF R.L., CAULEY J.A. and PETTINGER M.: "Lack of a relation between vitamin and mineral antioxidants and bone mineral density: Results from the Women's Health Initiative." Am. J. Clin. Nutr., 82: 581-8, 2005.

50- SAHNI S., HANNAN M., BLUMBERG J., CUPPLES L., KIEL D. and TUCKER K.: "Protective effect of total carotenoid and lycopene intake on the risk of hip fracture: A 17-year follow-up from the Framingham Osteoporosis Study." J. Bone Miner. Res., 24: 1086-94, 2009. 


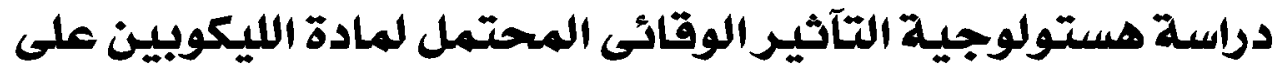

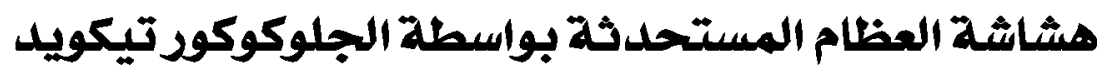 فى ذكر الجرذ الآبيض البيالغ}

المقدمة: يعتبر مرض هشاشة العظام واحد من آكثر آهراض العظام شيوعا، وتتميز بإنخفاض وتآكل كتة العظام مع حدوث مضاعفات

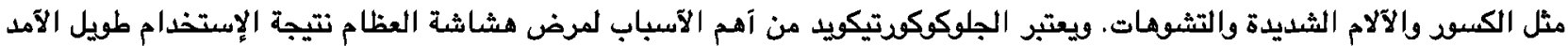

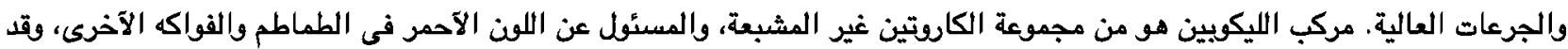

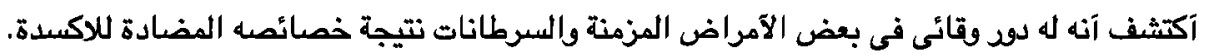

الهدف من العهل: هو دراسة التآثير الوقائى المحتمل لمركب الليكوبين على هشاتشة العظام المستحدثة بواسطة الجلوكوكوتيكويد فى ذكر الجرذ الآبيض البالغ.

المواد والطرق: تم إستخدام •ع من ذكود الجرذ البيضاء البالغة والتى قسمت إلى آربع مجموعات متساوية: المجموعة الآولى (الضابطة)

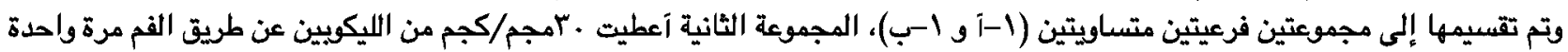

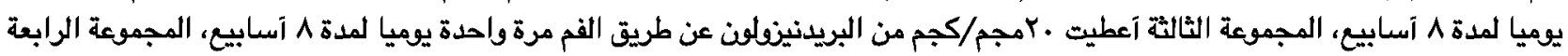

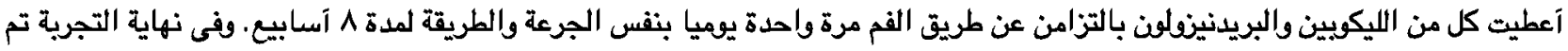

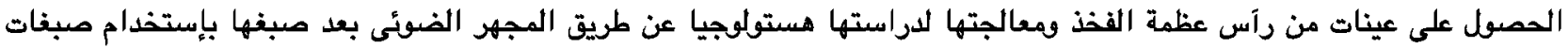

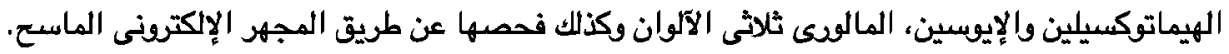

النتائج:كشف الفحص المجهرى الضوئى لعينات رآس عظمة الفخذ فى المجموعة الثالثة تغيرات تركيبية فى النسيج العظمى على هيئة

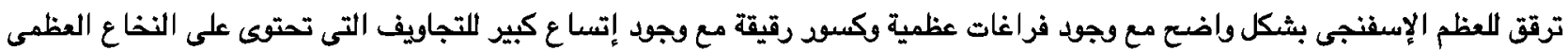

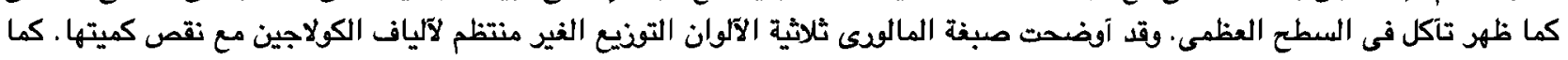

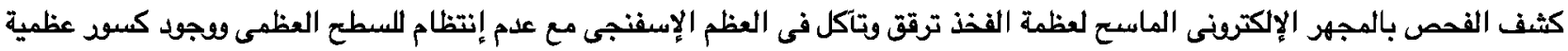
رقيقة وكذلك إتعاع كبير للتجاويف التى تحتوى على النخاع العظمى. مما يشبت وجود هشاشة اللعظام ناتجة عن إعطاء عقار البريدنينولمن.

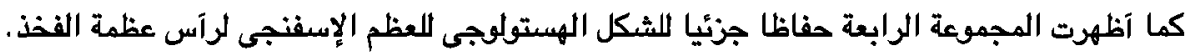
الإستتاج: هشاشة العظام الناتجة عن إعطاء الجلوكوكوتيكويد فى ذكر الجرذ الآيض البالغ يمكن التقليل منها جزئيا بالتناول المصاحب 